\title{
Contribution of clouds radiative forcing to the local surface temperature variability
}

OSCAR ROJAS, MARJOLAINE CHIRIACO, SOPHIE BASTIN, JUSTINE RINGARD

LATMOS/IPSL, UVSQ Université Paris-Saclay, Sorbonne Université, CNRS, 11 bd d'Alembert, Guyancourt, France

(c) (1) Online presentation EGU2020, 01.04.2020 - 30.05.2020 


\section{Motivation}

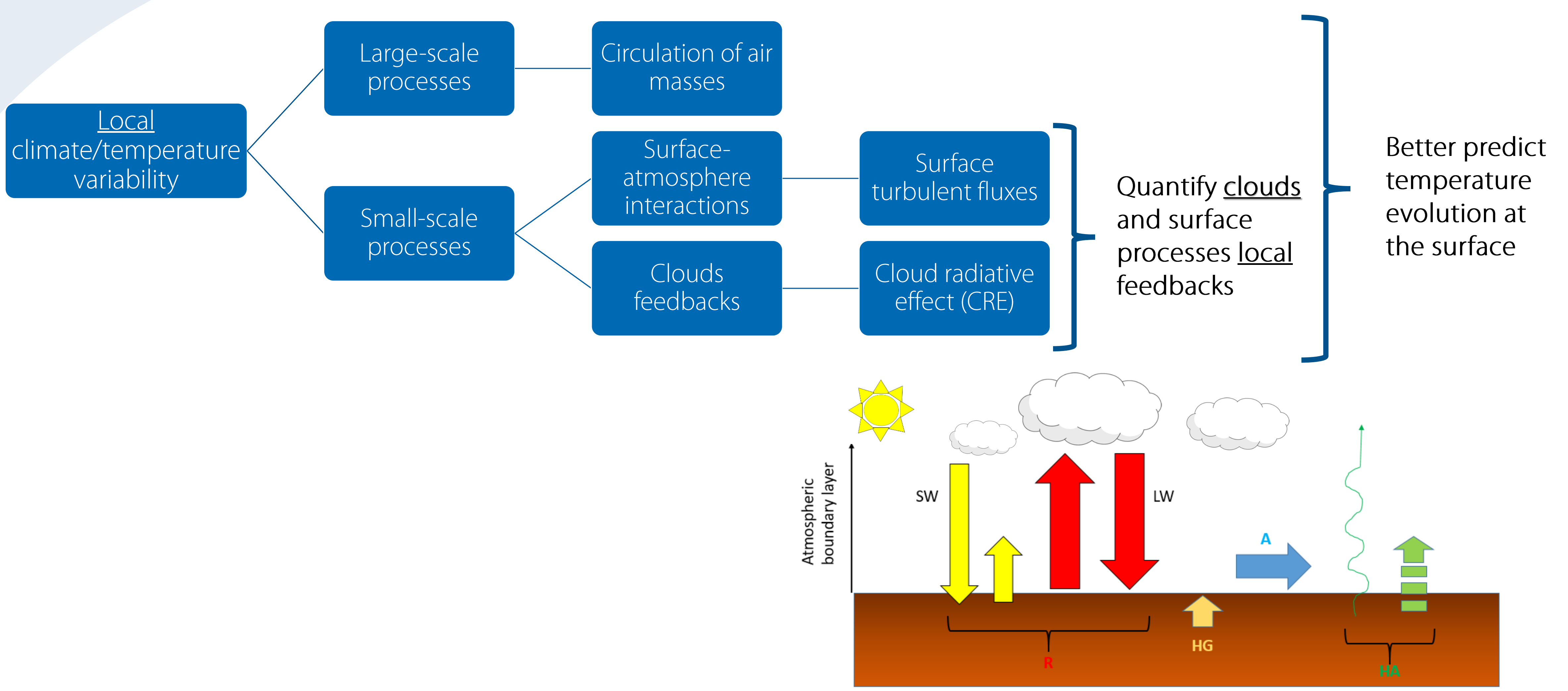




\section{Data}

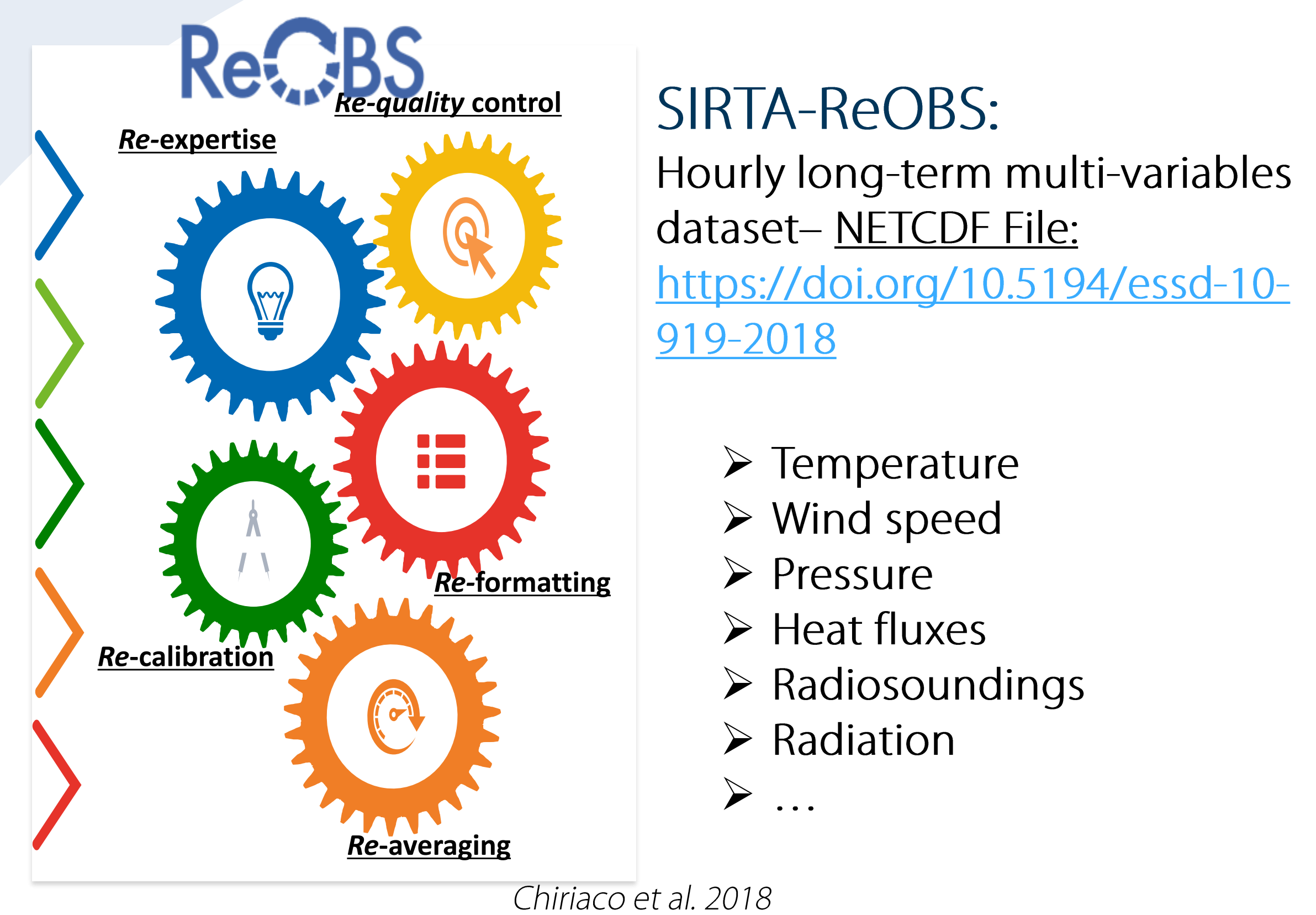

* All the necessary variables requested by the current study are available for the period going from January 2009 to February 2014 in an hourly scale

\section{SIRTA}

Observatory located in a semi-urban area 20-km SouthWest of Paris

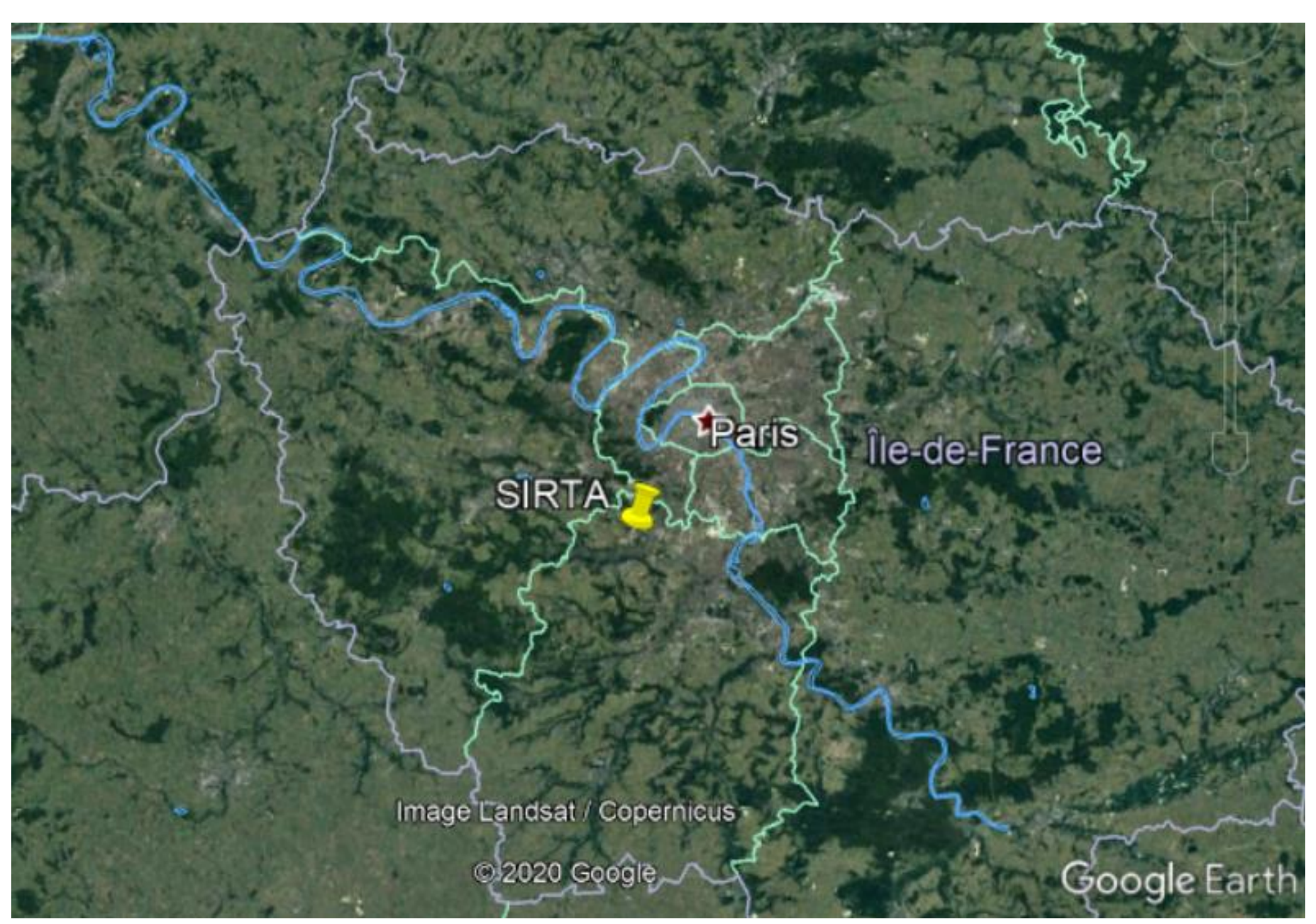




\section{General approach}

\section{Study steps:}

Creation of a model of temperature variability at $2 \mathrm{~m}$ at SIRTA

$$
\frac{\partial T_{2 m}}{\partial t}=R+H G+H A+A d v
$$

$$
\begin{aligned}
& \mathrm{R}=\text { Radiation }=\boldsymbol{R}_{\text {clear }} \text { sky }+\boldsymbol{R}_{\text {cloud }} \\
& \mathrm{HG}=\text { Ground heat exchange } \\
& \mathrm{HA}=\text { Atmospheric heat exchange } \\
& \mathrm{Adv}=\text { Advection }
\end{aligned}
$$

Main terms acting on the surface

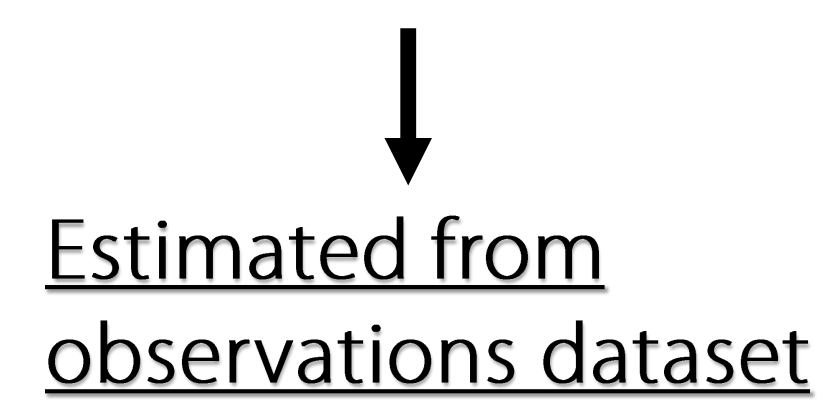

1. Creation of a model of temperature variability

2. Statistical evaluation of the model

3. Which term is predominant, particularly in relation to the seasons

4. The value of $\boldsymbol{R}_{\text {cloud }}$ and the conditions under which it predominates over the other terms

5. Cloud contribution and characterization 


\section{Term estimation}

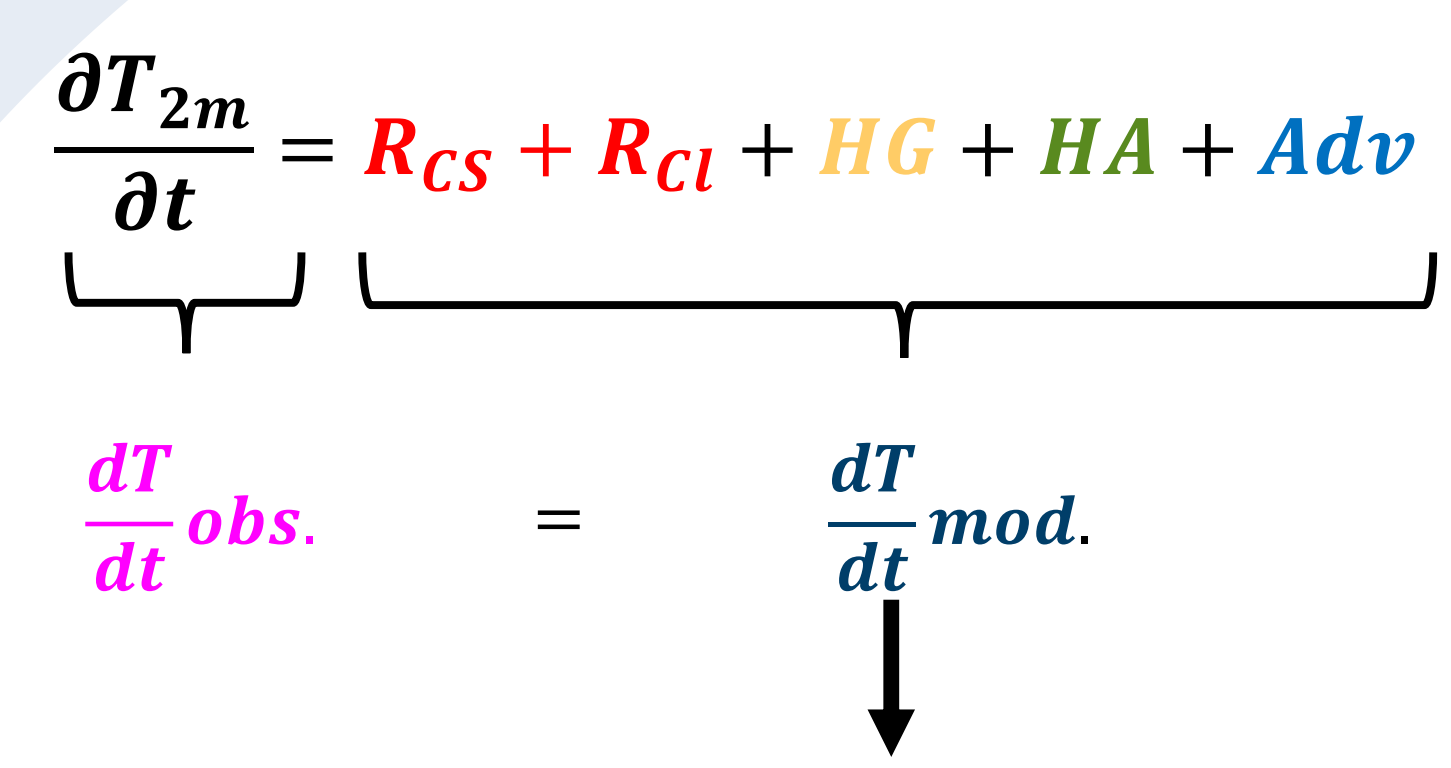

Both $\frac{d T}{d t}$ obs. and $\frac{d T}{d t} \bmod$. are estimated from SIRTA-ReOBS dataset

+ some assumptions on atmosphere stability, ground behavior, etc (a) Observations
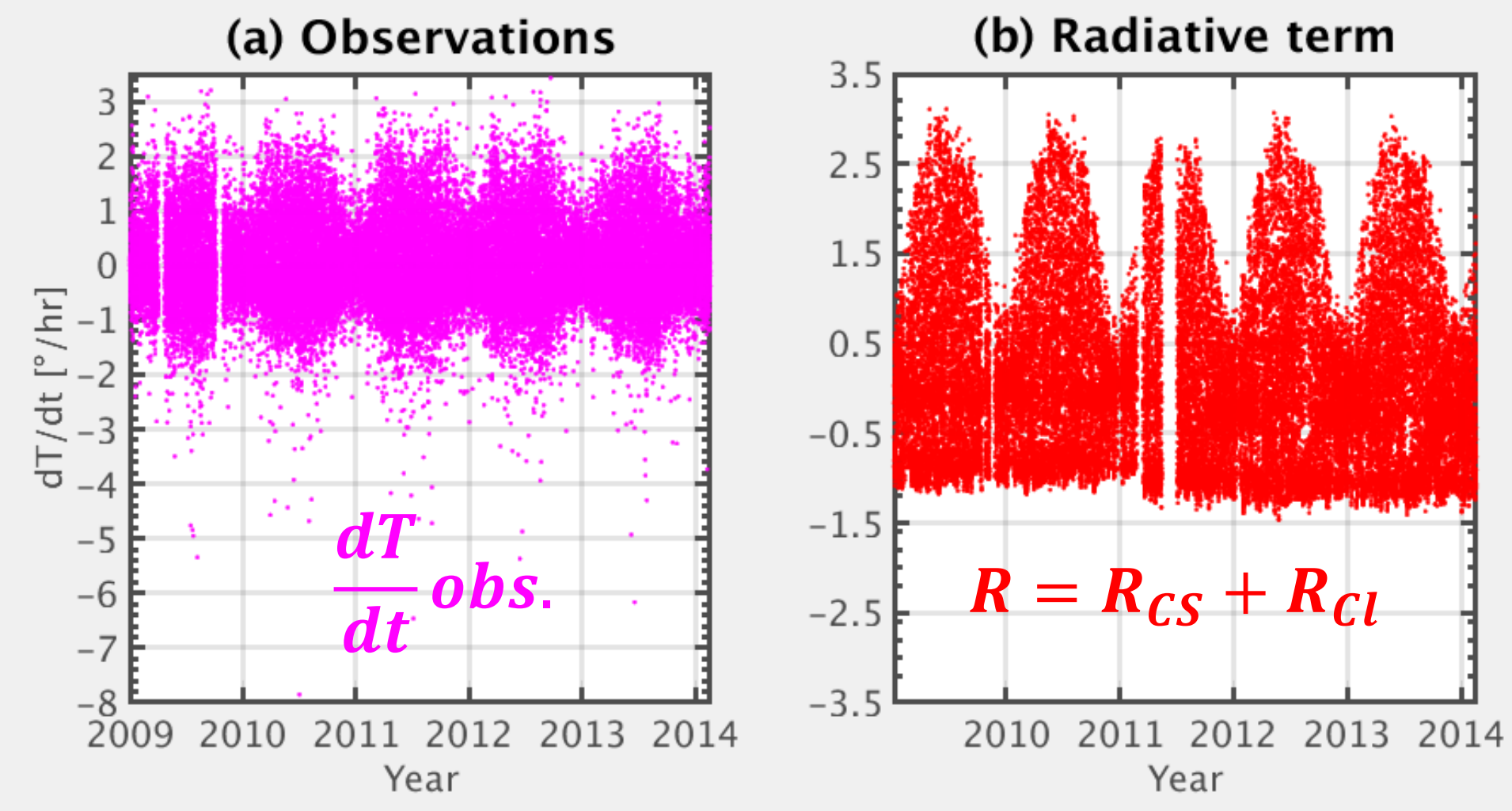

(d) Atmospheric heat exchange term

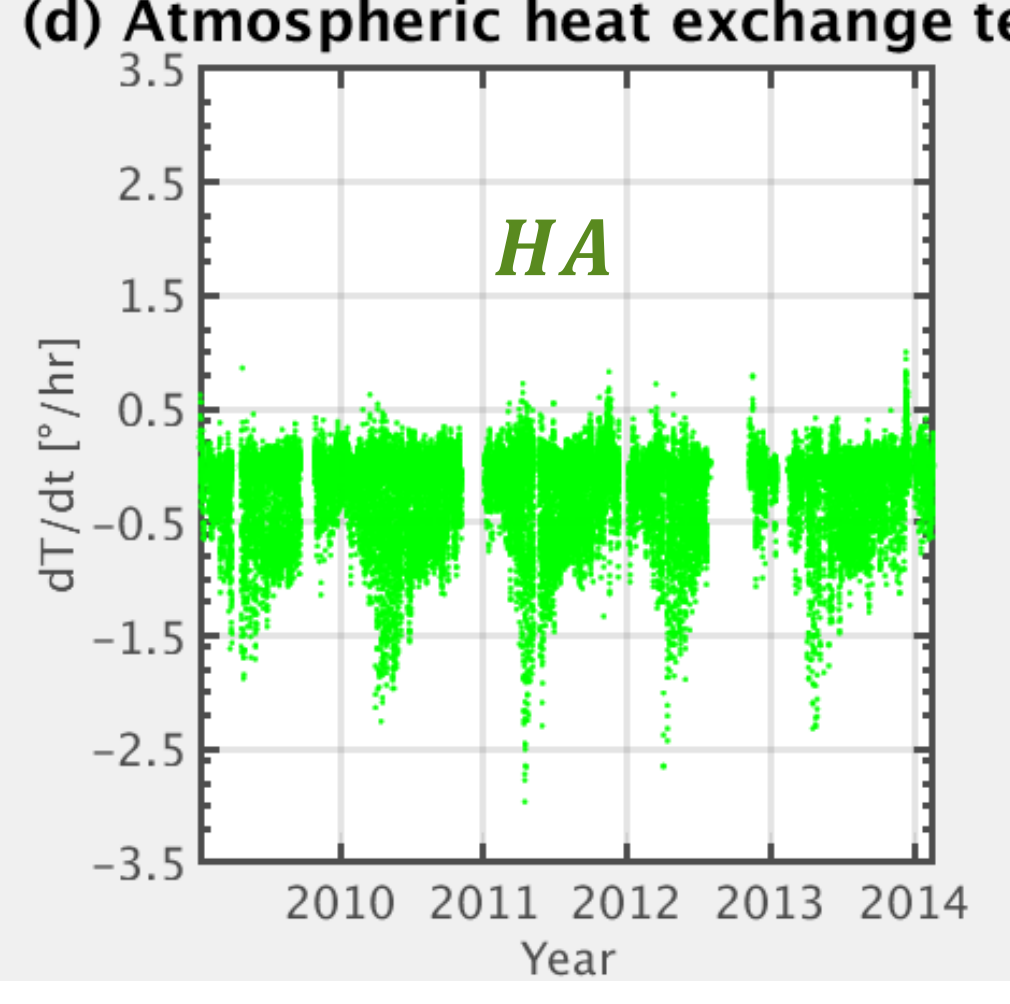

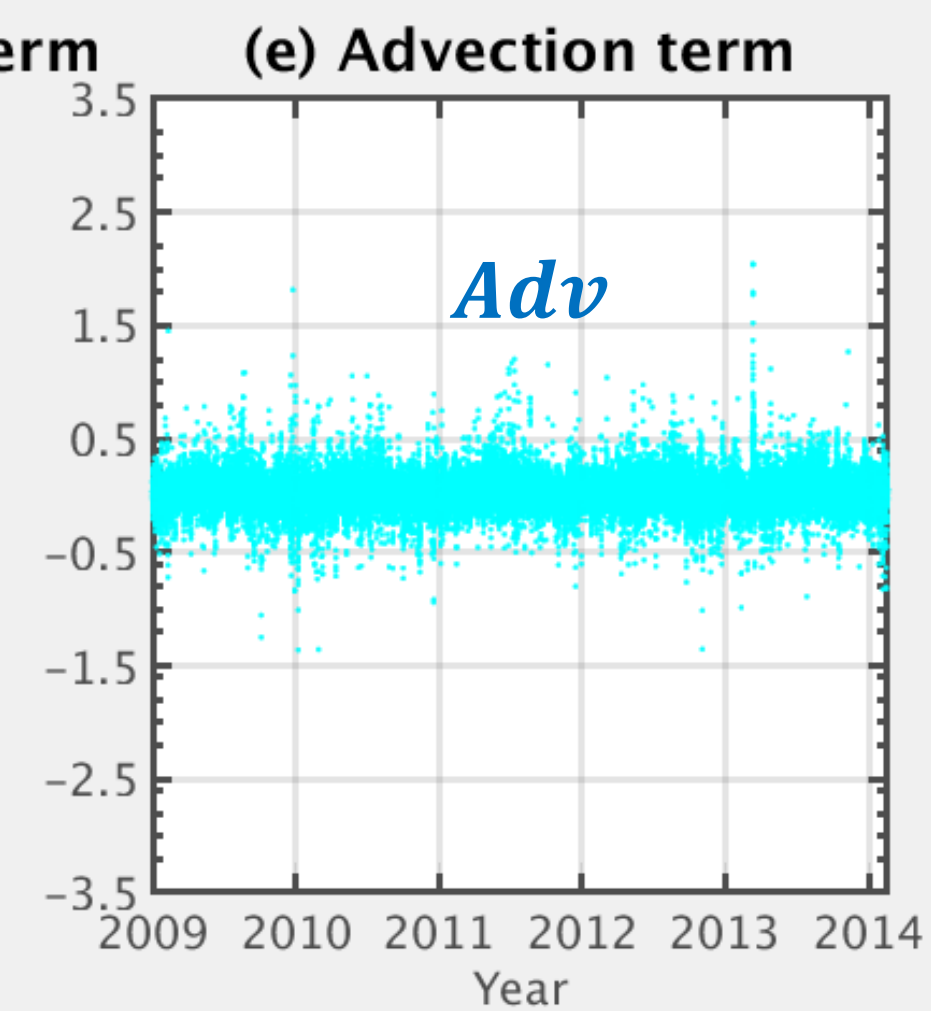

(c) Ground heat exchange term

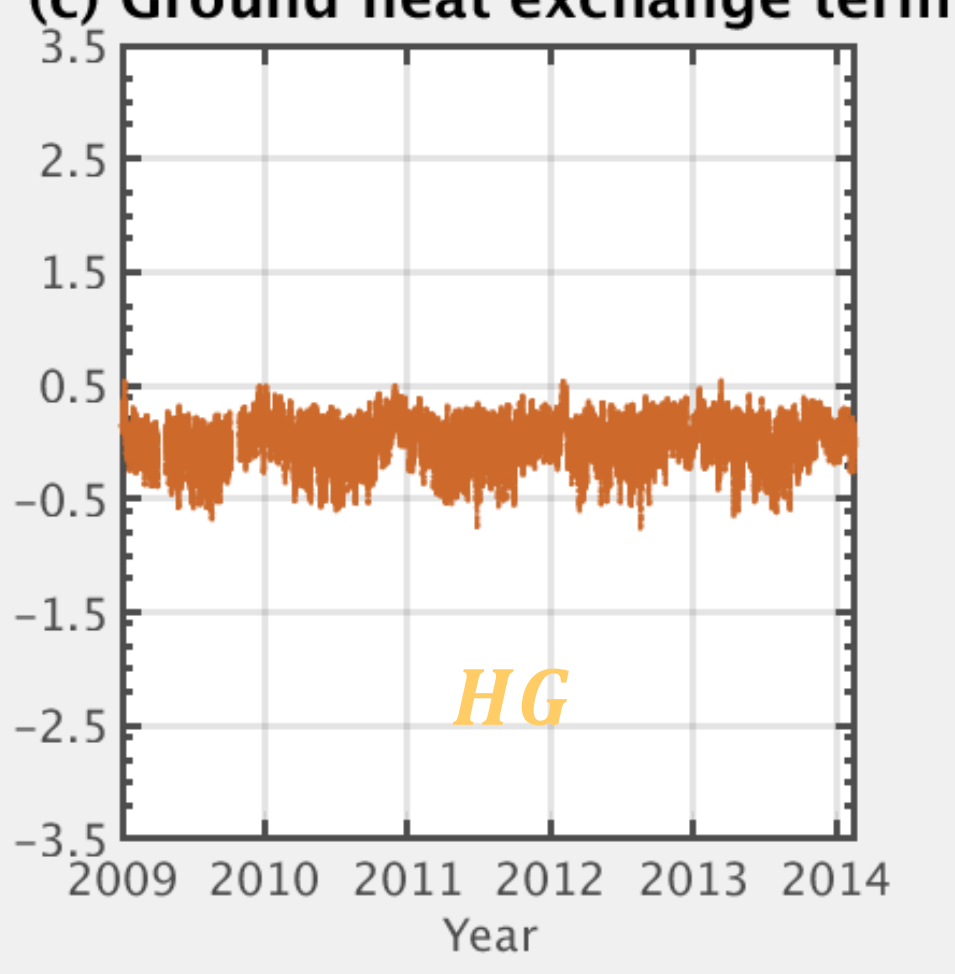




\section{Statistical evaluation of the model}

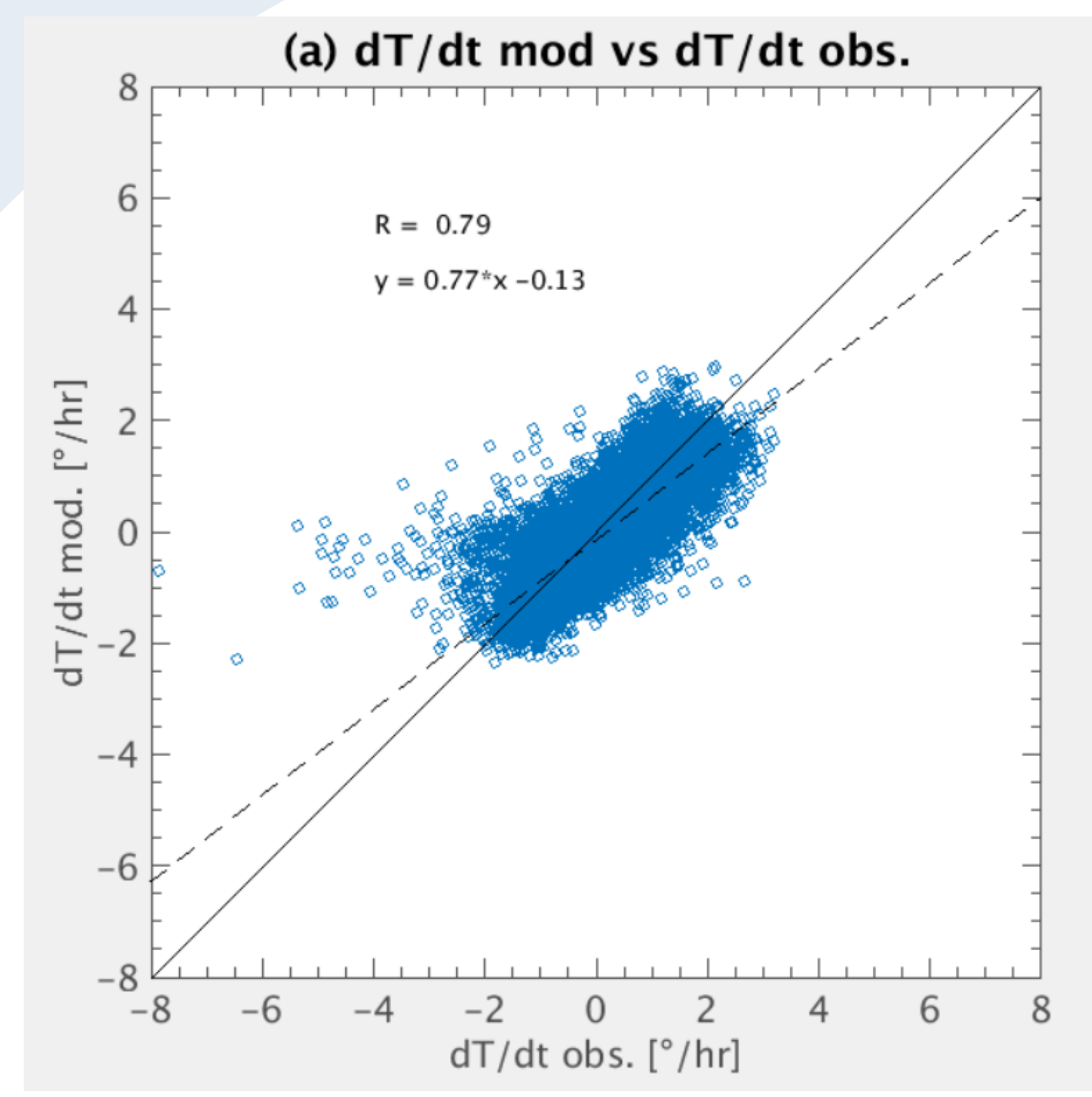

Good coefficient correlation between the model and the observations $(R=0,79)(a)$

\section{(c) (1)}

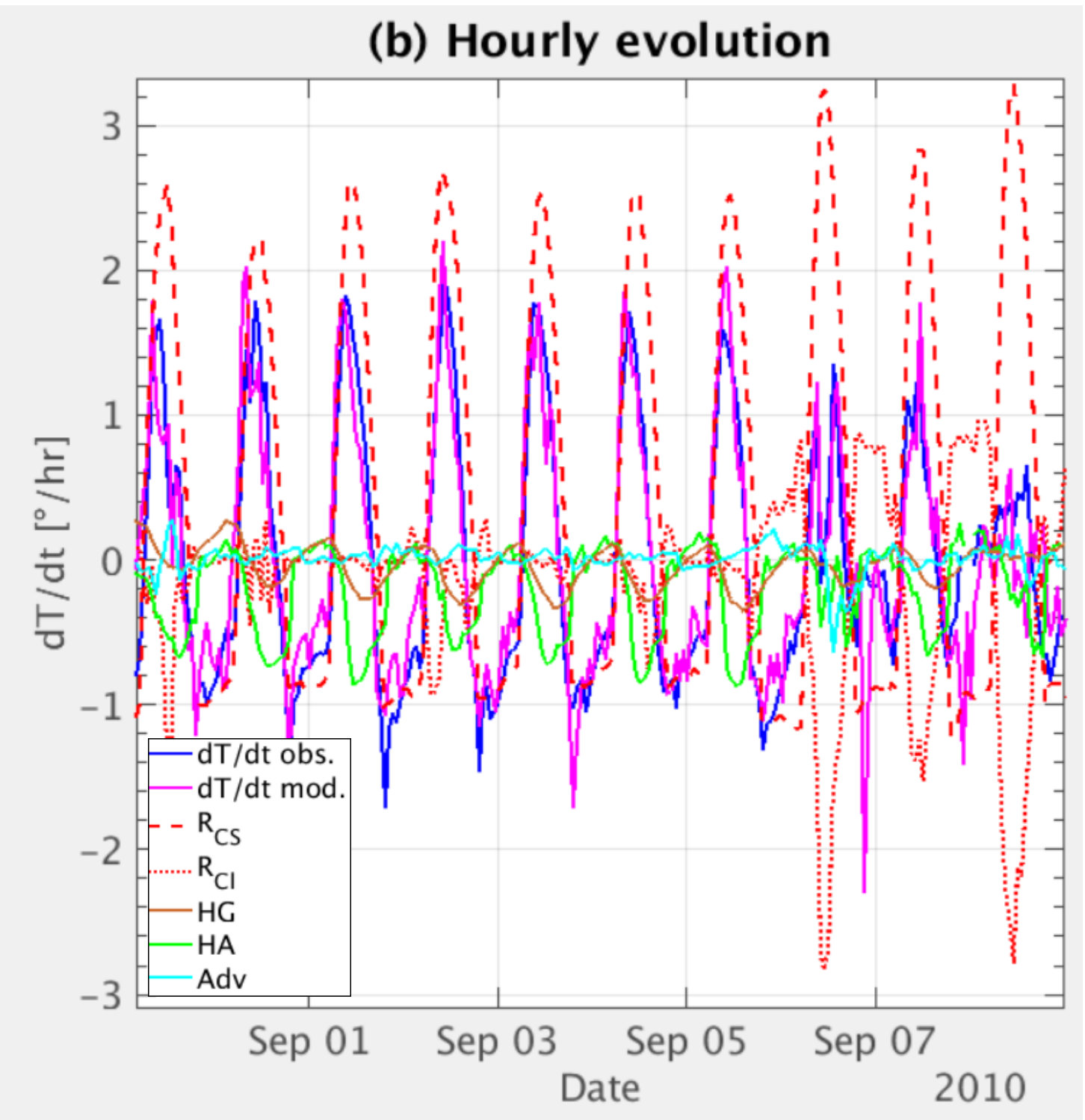

$\checkmark$ The model follows quite well the observations (b)

$\checkmark$ Variability of T mainly driven by $\mathrm{R}$ radiation on this time scale (b)

$\checkmark$ Marked strong diurnal cycle for $\boldsymbol{R}_{C S}$, and a weak one for $\mathrm{HA}(\mathrm{b})$
Statistics by season:

\begin{tabular}{c|c|c|c|}
\hline Season & Corr. Coeff. & $\begin{array}{c}\text { Bias } \\
\left({ }^{\circ} \mathrm{C} / \mathrm{hr}\right)\end{array}$ & $\begin{array}{c}\text { Standard deviation } \\
\left({ }^{\circ} \mathrm{C} / \mathrm{hr}\right)\end{array}$ \\
\hline Summer & 0,82 & $-0,20$ & 0,55 \\
\hline Fall & 0,79 & $-0,23$ & 0,46 \\
\hline Winter & 0,67 & $-0,31$ & 0,43 \\
\hline Spring & 0,80 & $-0,25$ & 0,53 \\
\hline
\end{tabular}

Good coefficient correlation for all seasons ( $\sim \mathbf{0 , 8 0}$ on average) except for winter 


\section{Results: 1) Relative weight of each term on temperature variability}
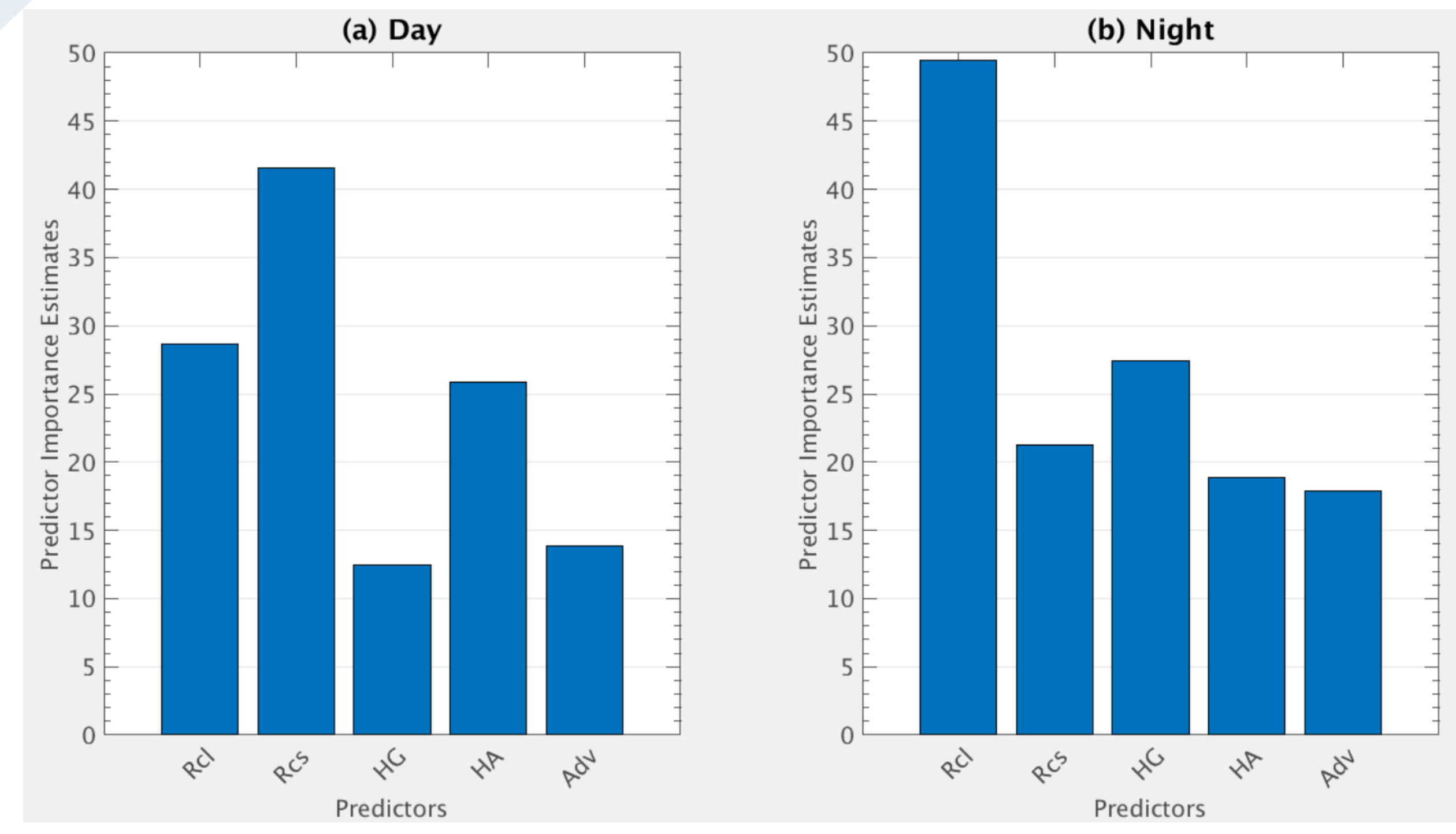
Day:
$\checkmark \boldsymbol{R}_{\boldsymbol{C S}}$ contributes the most, followed by $\boldsymbol{R}_{\boldsymbol{C l}}$ and HA

Night:

$\checkmark \boldsymbol{R}_{\boldsymbol{C l}}$ dominates temperature change

$\checkmark \mathbb{H G}$ contributes by warming the surface

Bootstrapped-aggregated decision trees Main advantage: Reduce of overfitting Objective: Show the importance* of each term on $\frac{d T}{d t} \bmod$. 


\section{Results: 2) Diurnal cycle of each term}

(a) DJF

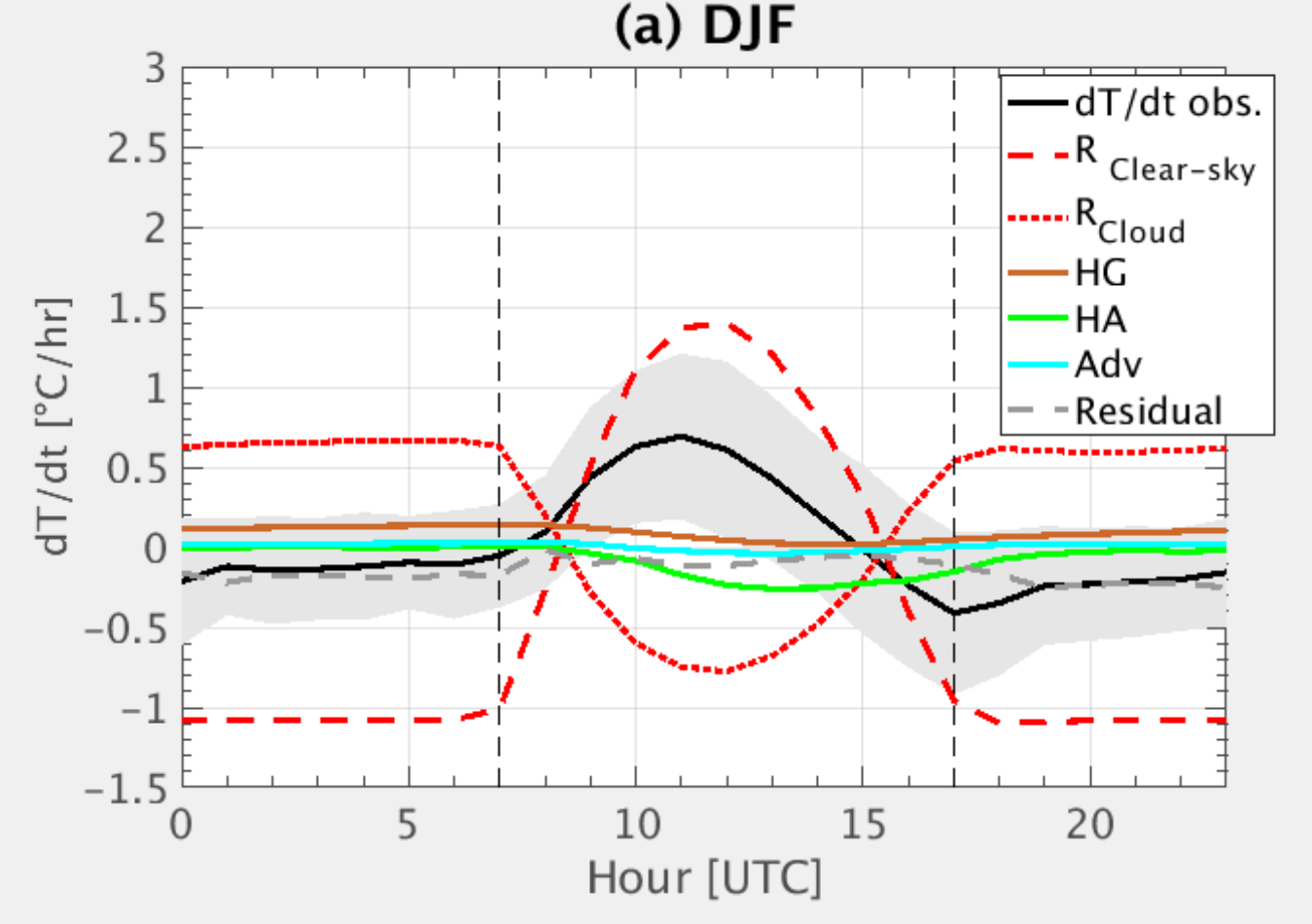

(c) JJA

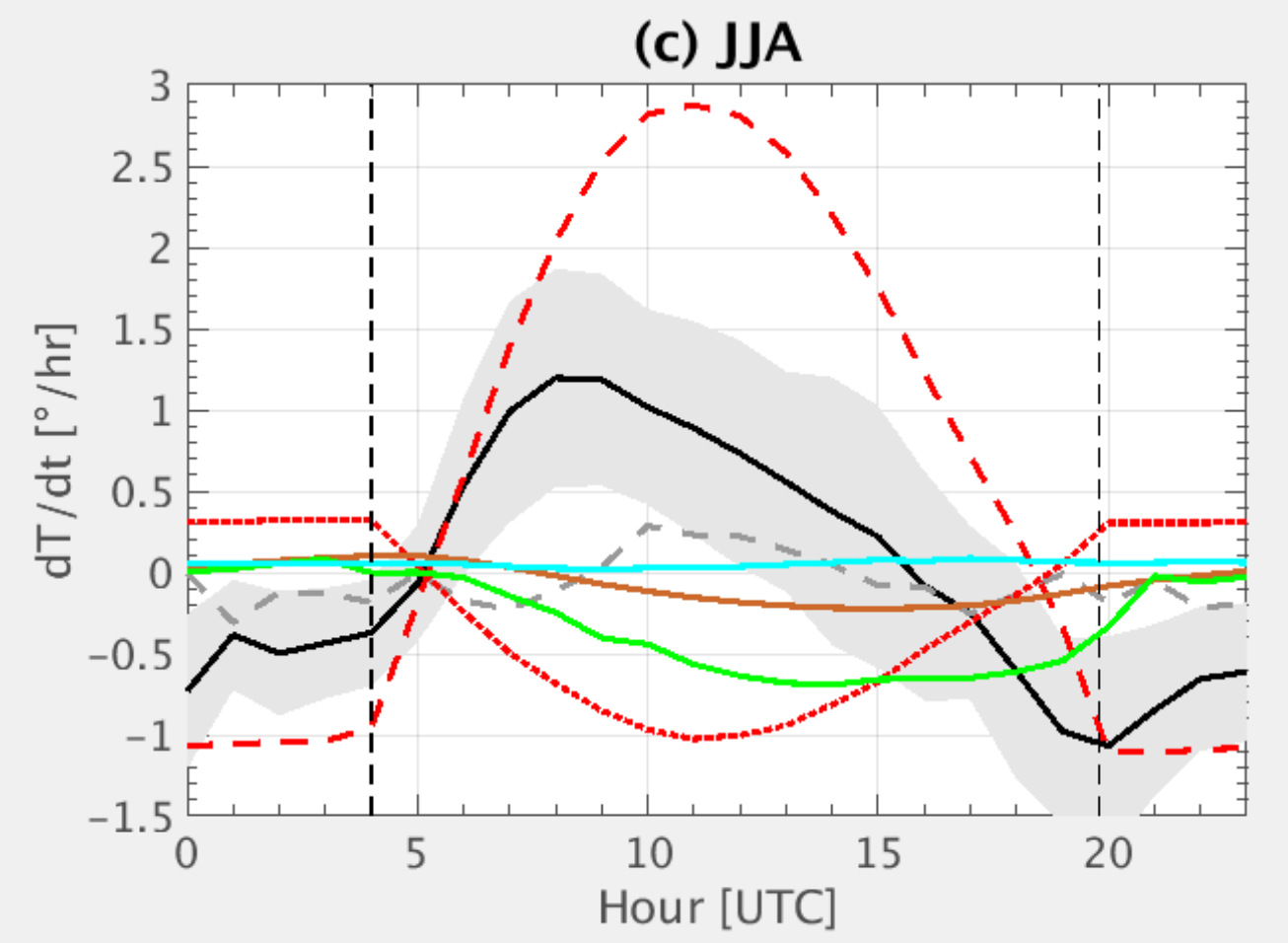

(b) MAM

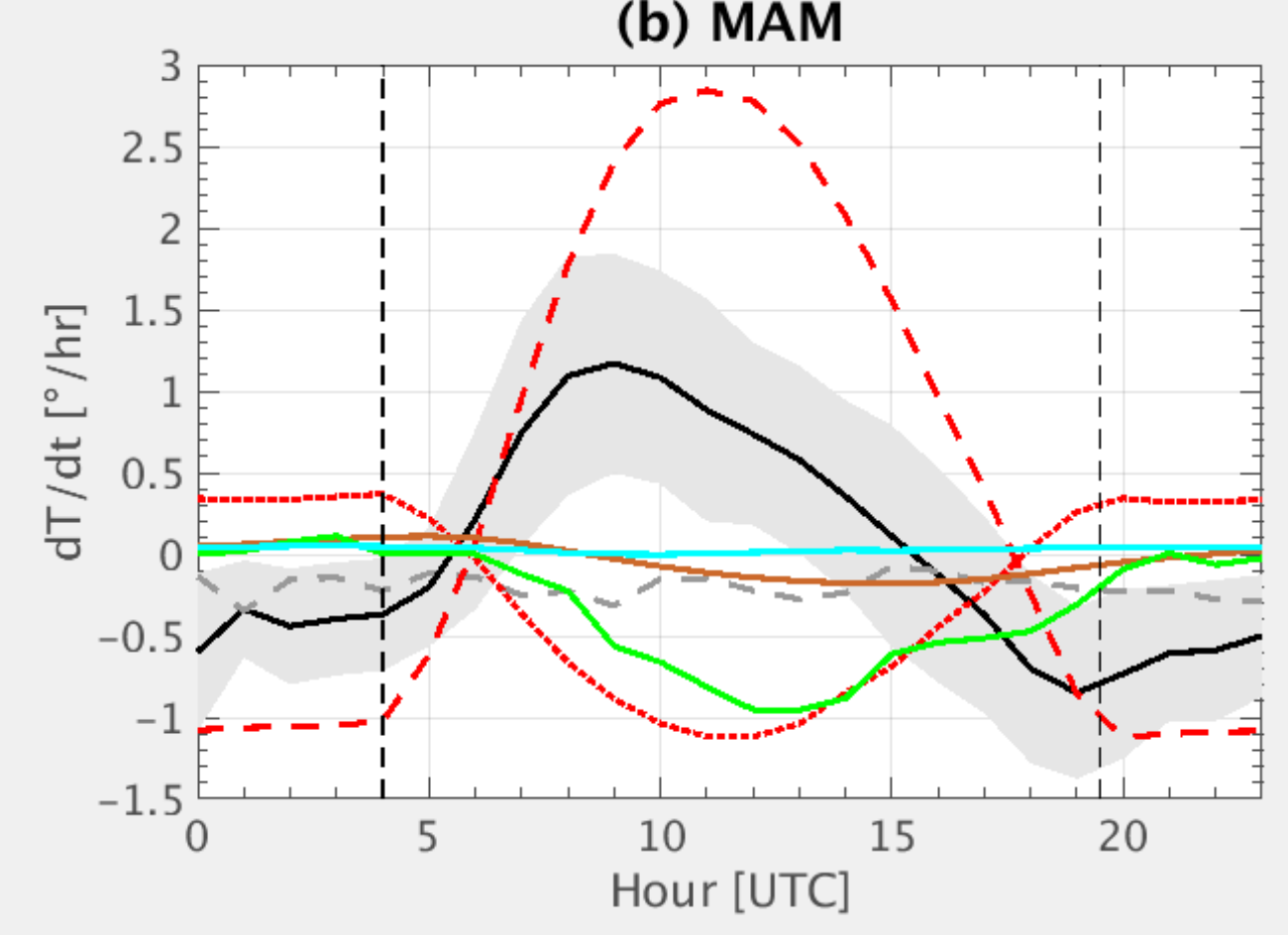

(d) SON

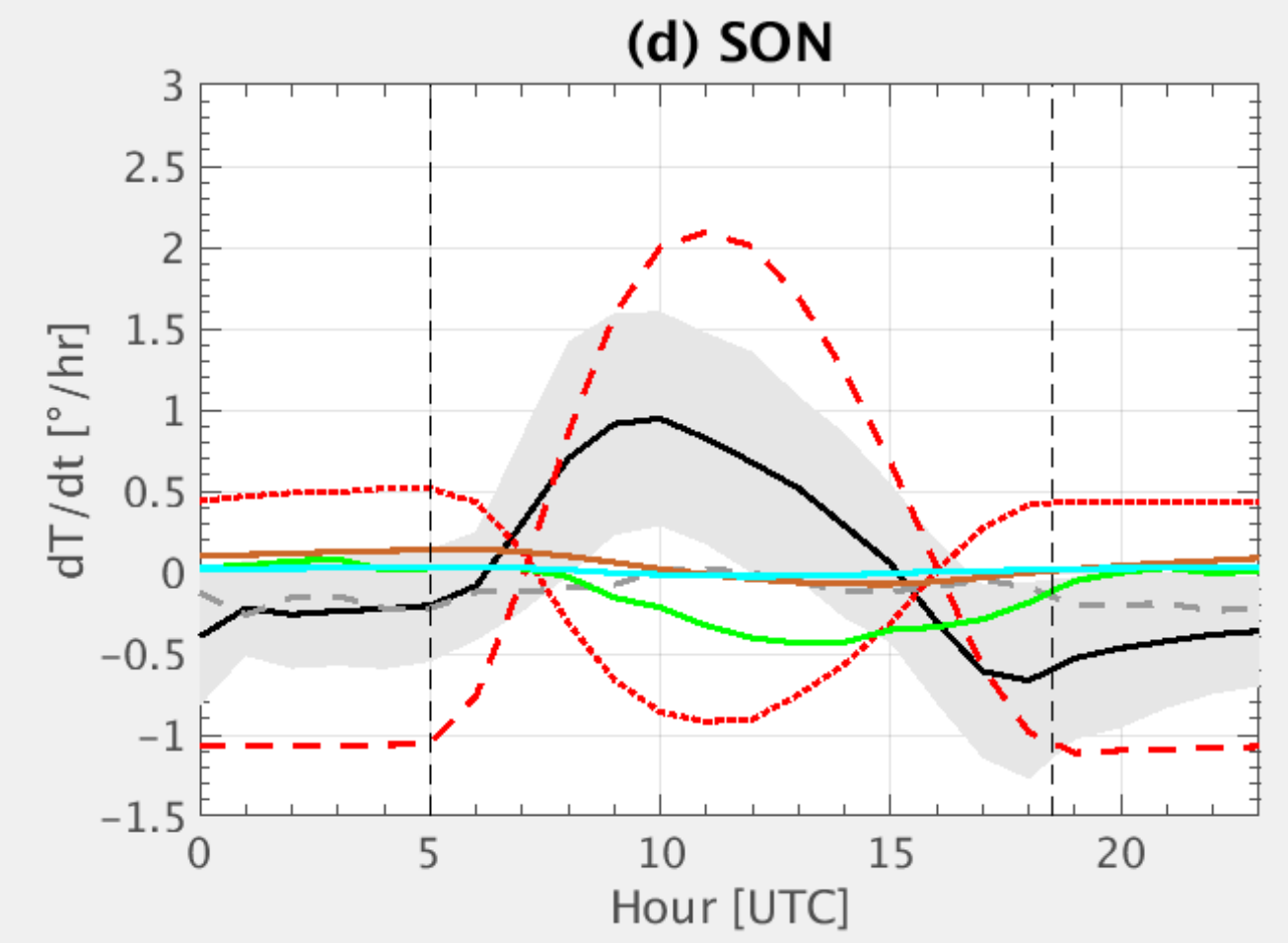

$\checkmark$ Residual is generally weak

$\checkmark$ Clouds are the main modulator of the variability of T at the SIRTA at this time scale (one hour).

$\checkmark$ HA term becomes important in spring and summer in the late afternoon -> + of sensible and latent heat fluxes

\section{(c) $\underset{\mathrm{BY}}{(\mathrm{P}}$}




\section{Results: 3) Monthly-hourly cycle of each term}

(a) $R_{\text {clear-sky }}$

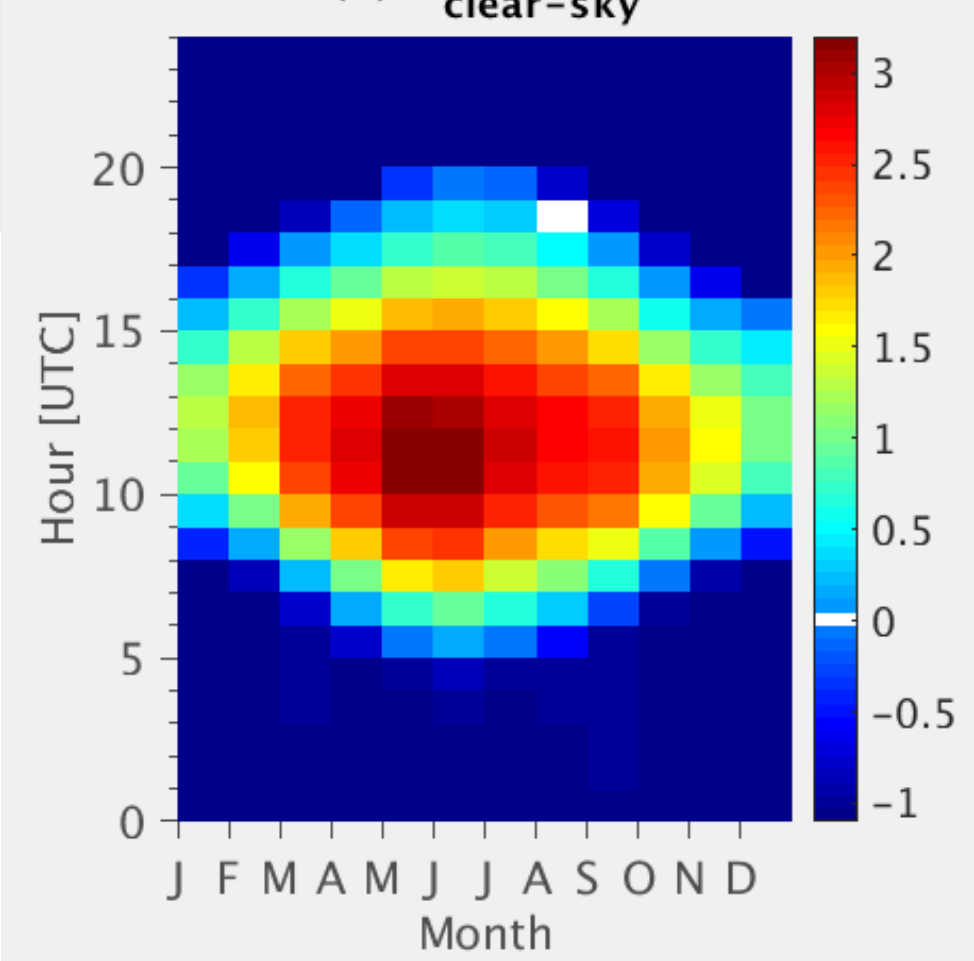

(d) HA

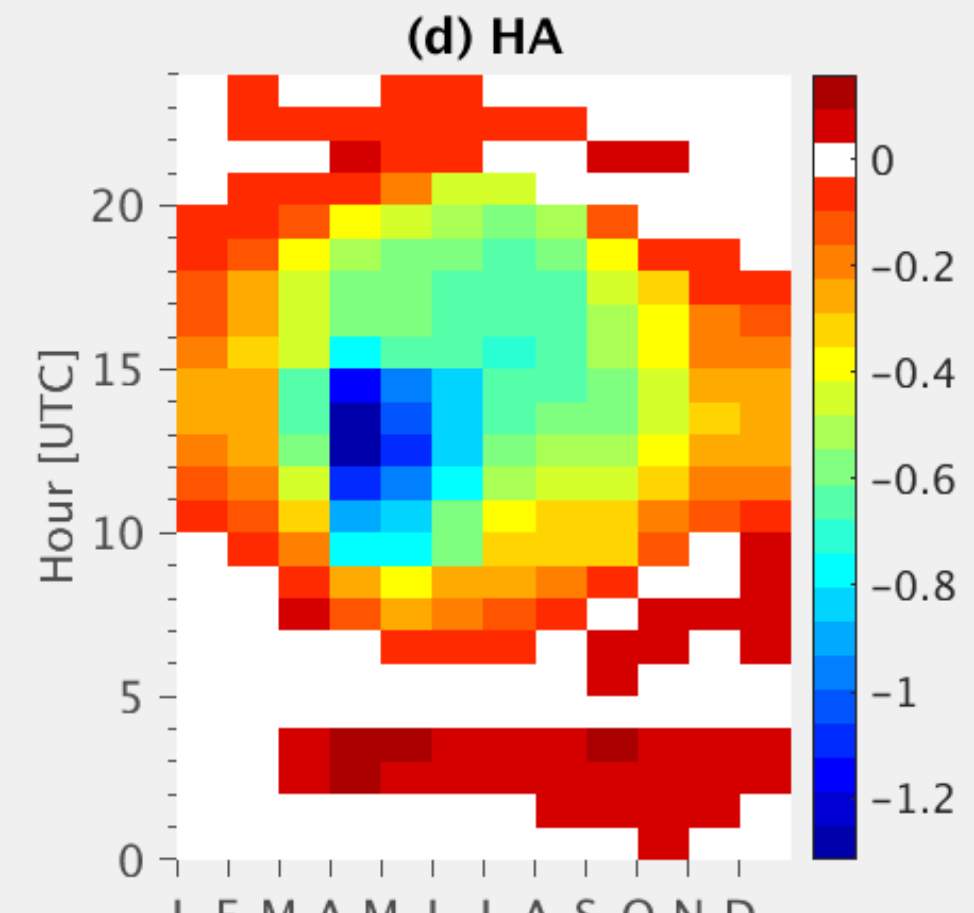

J F MAM J JASOND

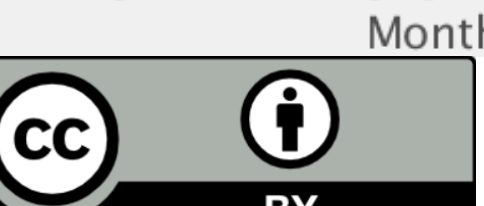

(b) $\mathrm{R}_{\text {cloud }}$

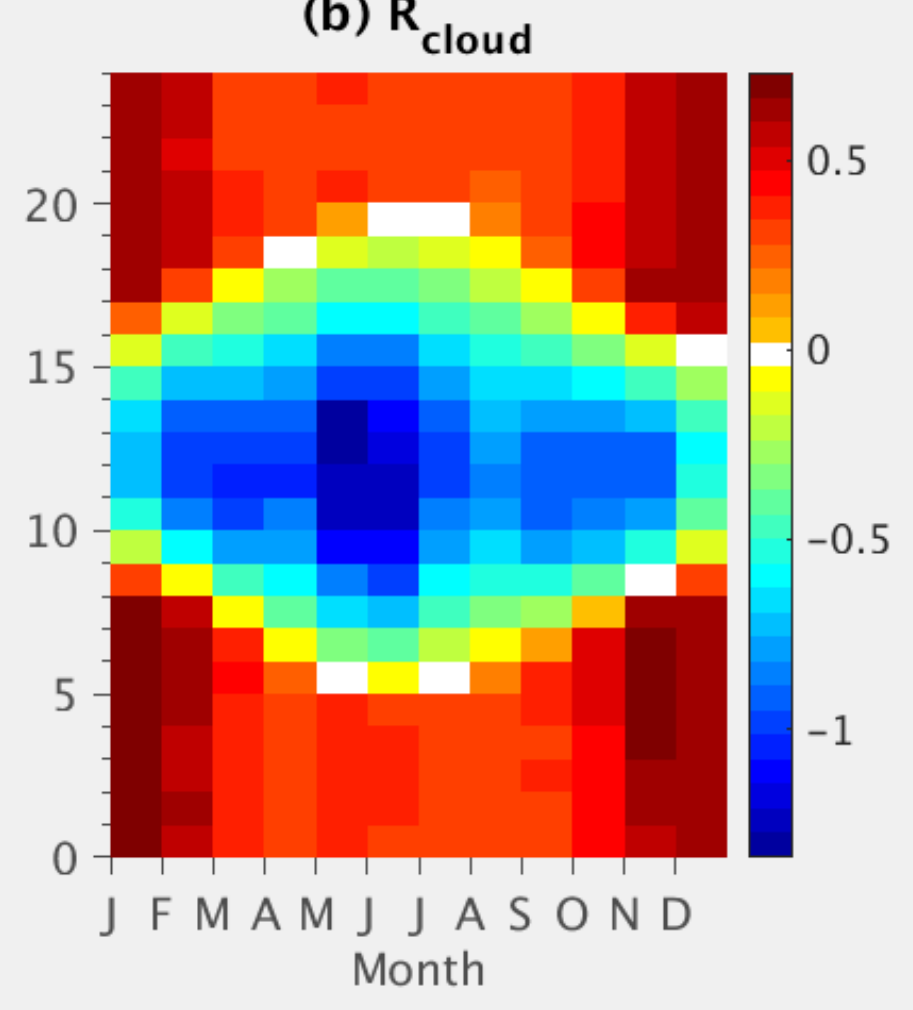

(e) Advection

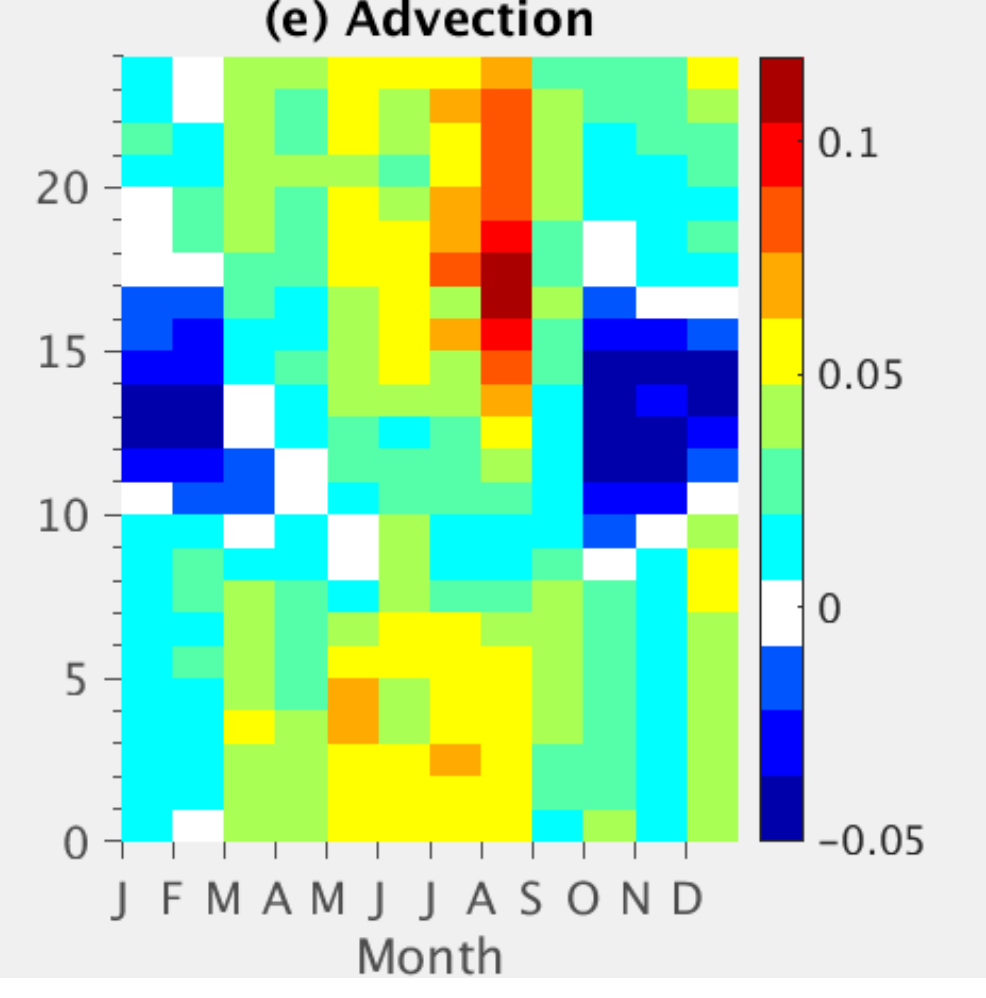

(c) HG

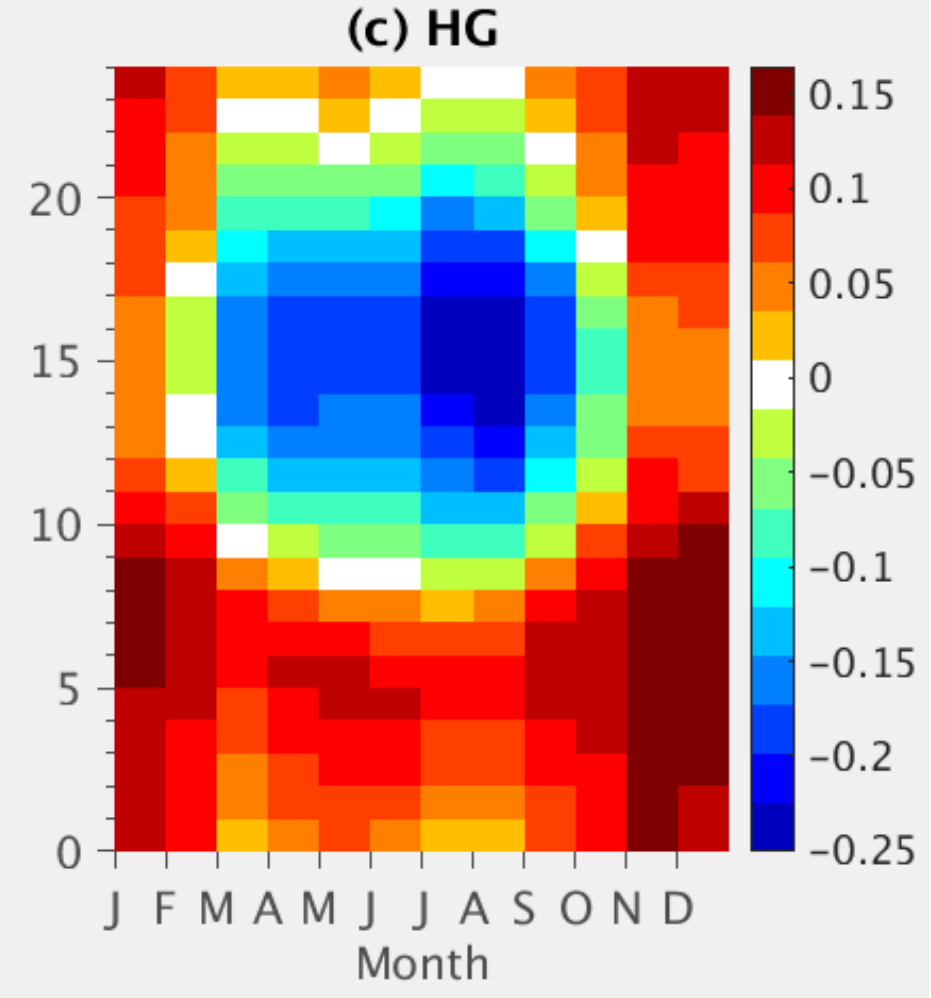

- All terms have a clearly marked monhtly-hourly cycle

- Maximum positive (negative) contribution of $\boldsymbol{R}_{C S}\left(\boldsymbol{R}_{C l}\right)$ in June at 10h00 UTC

- Clouds cool the surface up to $1,4^{\circ} \mathrm{C} / \mathrm{hr}$ (in average)

- HA term becomes important in Spring and its contribution during night is practically zero

- All terms except $\boldsymbol{R}_{\boldsymbol{C S}}$ warm the surface during the night 


\section{Results: 4) Specific cloud contribution in cloudy cases}
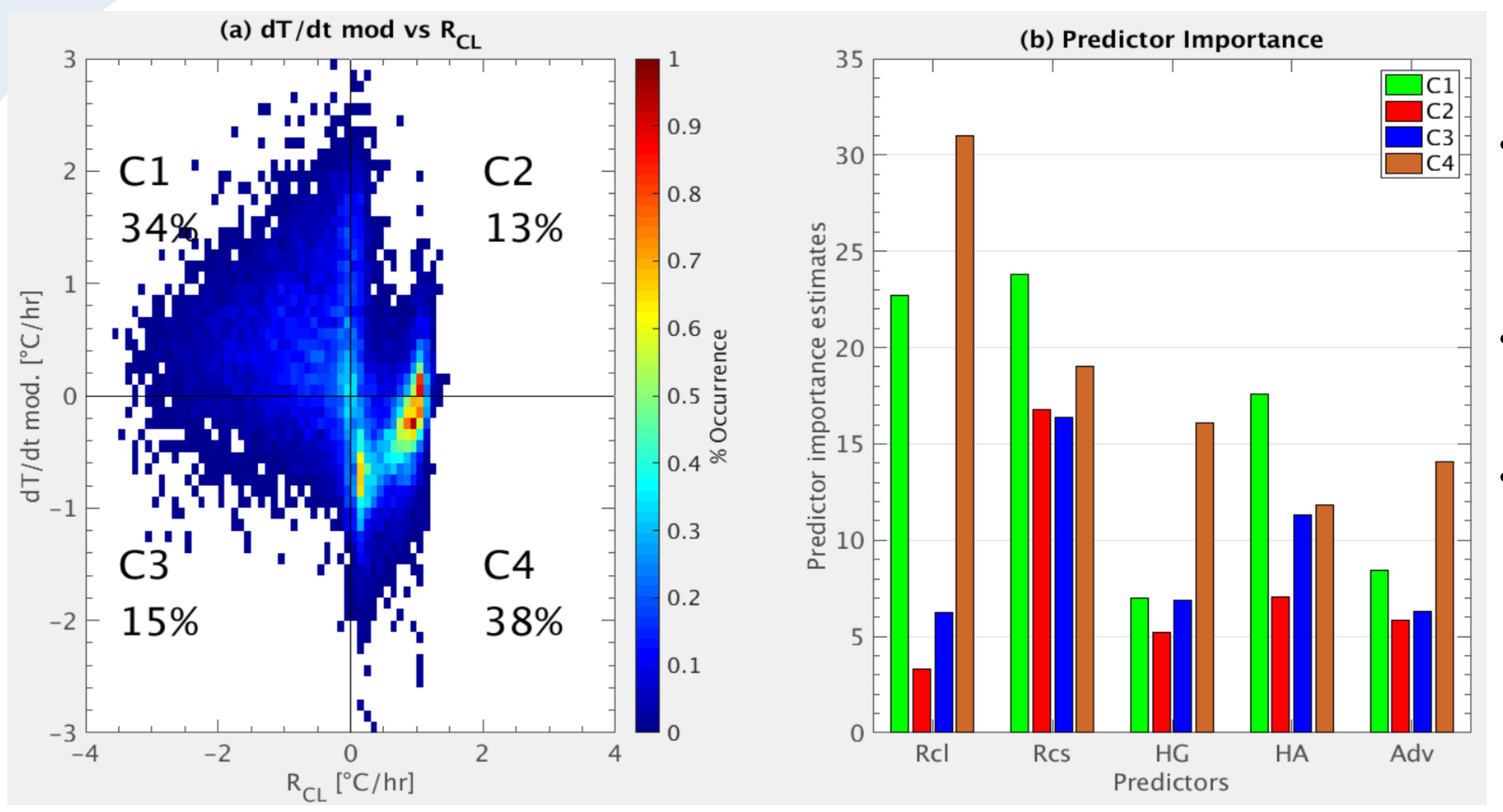

- Scatterplot of $\frac{d T}{d t} \bmod$. vs $\boldsymbol{R}_{C l}$ only for cloudy cases* and creation of four study categories (a)

- Clouds can cool (warm) up to $3,8^{\circ} \mathrm{C} / \mathrm{hr}\left(1,8^{\circ} \mathrm{C} / \mathrm{hr}\right)(\mathrm{a})$

- The treebagger analysis exposes a continuos dominance from $\mathrm{R}$ term for all the categories (b)

${ }^{*}$ Cloudy case: $\boldsymbol{C R} \boldsymbol{E}_{\boldsymbol{S W} / \boldsymbol{L W}} \geq \mathbf{5} \boldsymbol{W} / \boldsymbol{m}^{2}$

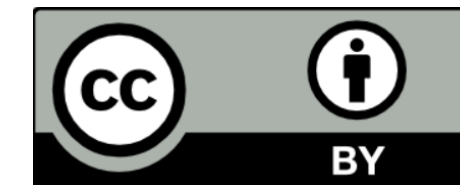




\section{Summary}

- Development of a model to estimate the different sources of temperature variability at SIRTA, based almost entirely on observations.

- Estimates and adjustment of all components characterizing this local variability (SIRTA-ReObs + ERA5)

- Good results for the hourly temperature variability: good correlation coefficient and a weak residual for all seasons

- Overall, the model tends to underestimate the observations: probably because of the important lack on some variables

○ For all seasons, clouds are the main modulator of temperature variability over the time scale considered, warming for both night and day, whereas they never cool during night

O Other terms act as modulators of $\boldsymbol{R}_{C S}$ but with a much lower contribution

- All terms remain necessary in order to obtain the best coefficient estimator between the directly measured observations and the method

- Temperature diurnal cycle less marked when cloud cover is important, corresponding to clouds with high amount of liquid water 
Appendix

(c) (i) 


\section{Variables used as inputs for the model}

(c)

\begin{tabular}{|c|c|c|}
\hline Variable, unit & Notation & \begin{tabular}{|l} 
SIRTA-ReOBS \\
Available Data \\
from 2009 to \\
2014, in $\%$
\end{tabular} \\
\hline $2 \mathrm{~m}$ air temperature, $\mathrm{K}$ & $\mathrm{T}_{2 \mathrm{~m}}$ & 97 \\
\hline Soil temperature below the ground, $\mathrm{K}$ & $\mathrm{T}_{\mathrm{s}}$ & 99 \\
\hline $\begin{array}{l}\text { Temperature at the mixing layer } \\
\text { height }^{*}, \mathrm{~K}\end{array}$ & $\mathrm{~T}_{\mathrm{H}}$ & 71 \\
\hline $\begin{array}{l}\text { Surface downwelling LW radiation, } \\
\mathrm{W} / \mathrm{m}^{2}\end{array}$ & $\mathrm{~F}_{\mathrm{LW}}^{\downarrow}$ & 100 \\
\hline $\begin{array}{l}\text { Surface downwelling SW radiation, } \\
W / \mathrm{m}^{2}\end{array}$ & $\mathrm{~F}_{S W}^{\downarrow}$ & 100 \\
\hline Surface upwelling $L W$ radiation, $W / \mathrm{m}^{2}$ & $\mathrm{~F}_{\mathrm{LW}}^{\uparrow}$ & 91 \\
\hline Surface upwelling SW radiation, $\mathrm{W} / \mathrm{m}^{2}$ & $\mathrm{~F}_{\mathrm{SW}}^{\uparrow}$ & 94 \\
\hline $\begin{array}{l}\text { Surface downwelling LW radiation for } \\
\text { clear sky, } \mathrm{W} / \mathrm{m}^{2}\end{array}$ & $\mathrm{~F}_{\mathrm{LW}, \mathrm{cs}}^{\downarrow}$ & 97 \\
\hline $\begin{array}{l}\text { Surface downwelling SW radiation for } \\
\text { clear sky, } \mathrm{W} / \mathrm{m}^{2}\end{array}$ & $\mathrm{~F}_{\mathrm{SW}, \mathrm{CS}}^{\downarrow}$ & 97 \\
\hline $\begin{array}{l}\text { Surface upward sensible heat flux, } \\
\mathrm{W} / \mathrm{m}^{2}\end{array}$ & $\mathrm{~F}_{\text {sens }}$ & 73 \\
\hline Surface upward latent heat flux, W/m² & $\mathrm{F}_{\text {lat }}$ & 5 \\
\hline Mixing layer depth, $m$ & MLD & 71 \\
\hline
\end{tabular}




\section{Data availability}

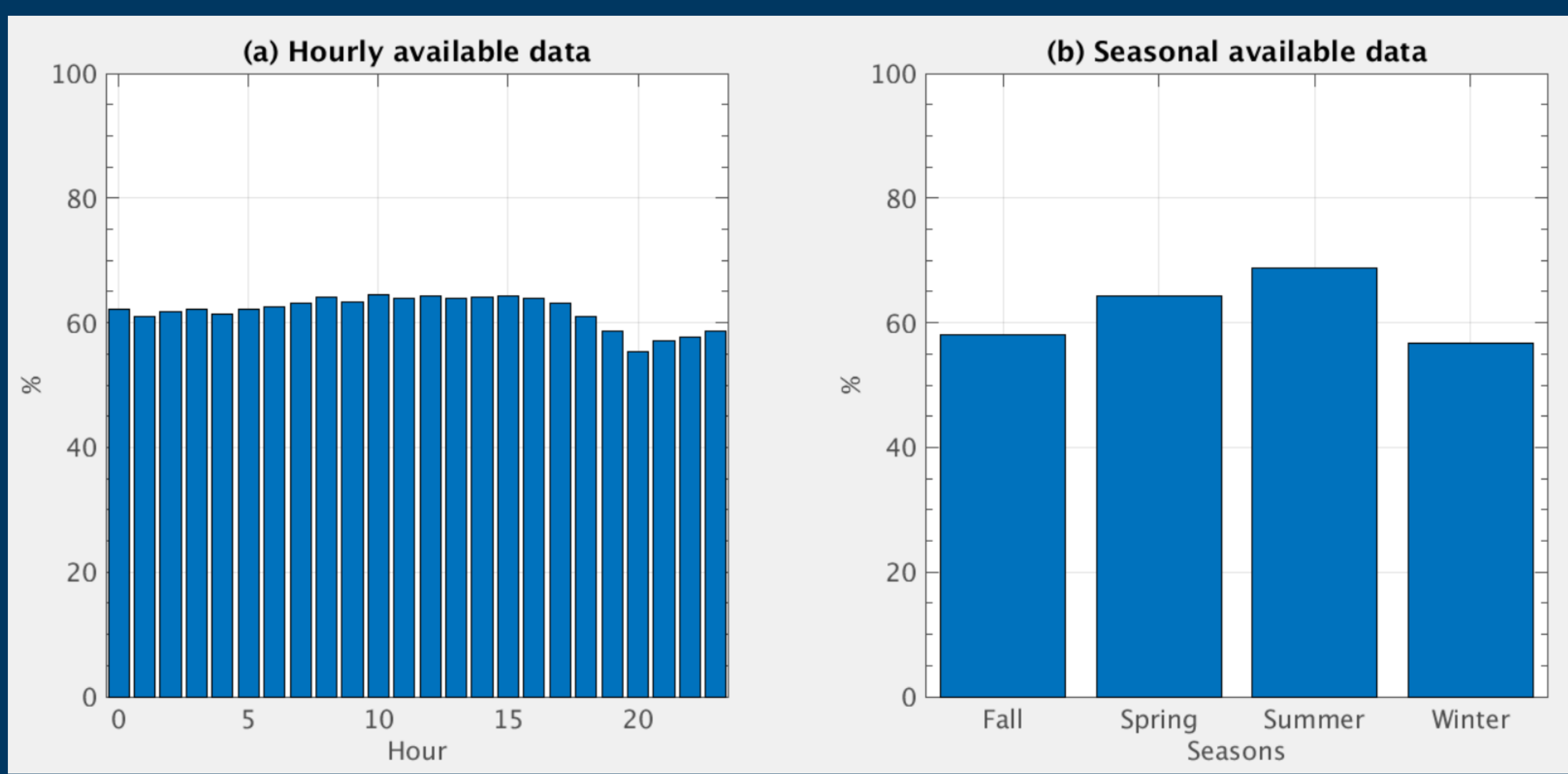

(c) (1) 


\section{Term estimation}

\section{Radiative term}

$R=\frac{\alpha+1}{c_{p} \rho M L H} \Delta F_{N E T}$

$\Delta F_{N E T}=S W \downarrow-S W \uparrow+L W \downarrow-L W \uparrow$ $M L H$ : Mixed layer height

$\boldsymbol{c}_{\boldsymbol{p}}$ : Specific heat of air

$\boldsymbol{\rho}$ : Air density

$\boldsymbol{\alpha}$ :Shape parameter of vertical

temperature profile
Ground heat exchange term

$H G=\frac{T_{s}-T_{2 m}}{\tau_{s}}$

$\boldsymbol{T}_{s}$ : Soil temperature below the ground

$\boldsymbol{T}_{\mathbf{2 m}}: 2 \mathrm{~m}$ air temperature

$\tau_{s}$ : relaxation timescale

\section{Advection}

$A d v=u_{10 m} \frac{\partial T_{2 m}}{\partial x}+v_{10 m} \frac{\partial T_{2 m}}{\partial y}$

$u, v:$ Horizontal wind speeds

\section{Atmospheric heat exchange term}

$$
H A=\frac{T_{M L H}-T_{2 m}}{\tau_{a}}
$$

$\boldsymbol{T}_{\boldsymbol{M L H}}:$ Temperature at the mixed layer height

$\boldsymbol{\tau}_{\boldsymbol{a}}$ : relaxation timescale*

$\tau_{a}=-\frac{T_{M L H}-T_{2 m}}{\left(F_{\text {sens }}+F_{\text {latent }}\right)(\alpha+1)} \rho C_{p} M L H$ 
$\tau_{a}$

$$
\begin{aligned}
& \frac{T_{\mathrm{MLH}}-T_{2 m}}{\tau_{a}}=-\frac{\alpha+1}{c_{p} \rho M L H}\left(F_{\text {sens }}+F_{\text {latent }}\right) \\
& \tau_{a}=-\frac{T_{M L H}-T_{2 m}}{\left(F_{\text {sens }}+F_{\text {latent }}\right) *(\alpha+1)} * \rho C_{p} M L H
\end{aligned}
$$


